\title{
artigo J JORNALISMO, REDES SOCIAIS E MOVIMENTOS DE OCUPAÇÃO GLOBAL: crise sistêmica na semiosfera contemporânea
}

Copyright () 2014 SBPjor / Associação Brasileira de Pesquisadores em Jornalismo

\author{
FELIPE DE OLIVEIRA \\ Unisinos \\ RONALDO HENN \\ Unisinos
}

\begin{abstract}
RESUMO - O artigo reflete sobre tensões geradas ao jornalismo com a emergência das redes sociais nos processos de construção social da realidade. O foco são acontecimentos suscitados pelo movimento Indignados, na Espanha, em 2012, durante o protesto " $25 \mathrm{~S}$ ", cuja demanda era uma nova assembleia constituinte. O garçom Alberto Casillas roubou a cena ao enfrentar a truculência policial, produzindo intensa repercussão nas redes e chamando a atenção do jornalismo. São dois os principais pontos de vista que, cotejados, levam a uma síntese possível acerca desse momento de crise: 1) a forma como o jornalismo representa os acontecimentos; 2) as possibilidades e implicações proporcionadas pelas redes nas dinâmicas mais amplas do jornalismo. O esforço reflexivo tem como base o conceito de semiose, de C. S. Peirce, e uma visão sistêmica inspirada na Semiótica da Cultura - especialmente em Yuri Lotman. Postula-se que, na semiosfera contemporânea em que se desenrolam complexos processos de semiose disparados por acontecimentos da ordem da realidade caótica, o jornalismo seja tensionado a rever suas práticas, sob o risco de perder a legitimidade que alcançou ao longo da história como mediador que produz certo tipo de conhecimento.
\end{abstract}

Palavras-chave: Jornalismo. Ciberacontecimento. Redes sociais. Crise. Realidade social.

\section{PERIODISMO, REDES SOCIALES Y MOVIMIENTOS DE OCUPACIÓN GLOBAL: cri- sis sistémica en la semiosfera contemporánea}

RESUMEN - El artículo reflexiona sobre las tensiones que la aparición de las redes sociales en los procesos de construcción social de la realidad ha generado en el periodismo. El estudio se centra en los acontecimientos suscitados por el movimiento de los Indignados en España en 2012, durante la protesta del 25S, cuya demanda fue una nueva asamblea constituyente. El camarero Alberto Casillas se convirtió en el protagonista al enfrentarse a la brutalidad policial, lo cual tuvo una importante repercusión en las redes y despertó el interés del periodismo. Dos son dos los principales puntos de vista que, contrastados, conducen a una posible síntesis acerca de este momento de crisis: 1) la forma en que el periodismo representa los acontecimientos; 2) las implicaciones y posibilidades que ofrecen las redes en las dinámicas más amplias del periodismo. El esfuerzo de reflexión se basa en el concepto de semiosis de C. S. Peirce y en una visión sistémica inspirada en la Semiótica de la Cultura —especialmente la de Yuri Lotman-. Se postula que en la semiosfera contemporánea, donde se desarrollan los complejos procesos de semiosis desencadenados por acontecimientos del orden de la realidad caótica, el periodismo se ve presionado a rever sus prácticas, ante el riesgo de perder la legitimidad lograda a lo largo de la historia como mediador que produce un cierto tipo de conocimiento sobre la realidad. Palabras clave: Periodismo. Ciberacontecimiento. Redes sociales. Crisis. Realidad social. 


\title{
JOURNALISM, SOCIAL NETWORKS AND GLOBAL OCCUPATION MOVEMENTS: a systemic crisis in the contemporary semiosphere
}

\begin{abstract}
This article ponders the tension created in journalism by the emergence of social networks in the processes of the social construction of reality. The focuses are the events kindled by the Indignados movement in Spain in 2012, during the "25S" protests, which called for a new constituent assembly. Waiter Alberto Casillas stole the scene by facing police truculence, and that had a great repercussion in the networks, attracting the attention of international journalism. There are two points of view which, when compared, lead to a possible synthesis about this moment of crisis: 1) the way journalism presents the events; 2) the possibilities and implications offered by the networks to the more ample dynamics of journalism. C. S. Peirce's concept of semiosis is the basis of the reflective effort, along with a systemic view inspired by the Semiotics of Culture - especially as in Yuri Lotman. It is postulated that in the contemporary semiosphere, in which complex processes of semiosis set off by events from the chaotic reality are unfolded, journalism has to review its practices, under pain of losing the legitimacy it has acquired throughout history as a mediator of a certain kind of knowledge. Keywords: Journalism. Cyberevent. Social networks. Crisis. Social reality.
\end{abstract}

\section{INTRODUÇÃO: O JORNALISMO NO PLANO DA SEMIÓTICA}

Este artigo faz um breve delineamento teórico de aproximação da semiótica ao estudo do jornalismo a partir, especialmente, de dois de seus principais autores: C.S. Peirce e Yuri Lotman. Ao mesmo tempo, reflete sobre a produção de acontecimentos nas práticas jornalísticas contemporâneas. Ao analisar materiais empíricos, pretende-se um movimento de síntese no cotejamento dessas perspectivas cujo diálogo se dá com base no conceito de semiose.

As práticas jornalísticas são entendidas, aqui, como um processo de significação do mundo - no pensamento peirceano, a semiose. Nesse território, ela se configura como um exercício de produção de signos que representam acontecimentos que se convertem em objetos da narrativa jornalística. Mobiliza aquilo que, entre outras elaborações teóricas, sustenta a tese de que o jornalismo é uma forma de conhecimento específica (MEDITSCH, 1997), que intervém na construção social da realidade (BERGER $E$ LUCKMANN, 1983).

Srour (1978) estabelece quatro premissas para a obtenção de conhecimento: a existência concreta do mundo, que independe daquilo que se conhece sobre ele; as determinações reais sobre o mundo, que constituem a estruturação interna dos seus fenômenos e suas lógicas; a possibilidade de apropriação cognitiva dessas 
determinações com fins de controle, previsão e intervenção; e o processo de conhecimento, a partir dessas lógicas, convertendose em produção - processo que se comporta como uma prática de apropriação e transformação do mundo.

Por sua vez, Lúcia Santaella (1996) percebe nessas premissas algo que está no núcleo dos postulados pragmatistas de Peirce e que caracterizam a semiose: os modos como a consciência/pensamento age e transforma essa operação cognitiva com o mundo em signos tem desdobramentos, inclusive, no campo da ação.

Admitir esses pressupostos implica em entender quais são as lógicas que orientam o jornalismo como gênero discursivo específico (BENETTI, 2008), ou ainda como linguagem - que, nas palavras de Lotman (1978, p. 35) é: "todo sistema de comunicação que utiliza signos ordenados de modo particular".

$\mathrm{Na}$ semiosfera contemporânea, novas tecnologias de comunicação e, sobretudo, as redes sociais na internet, constituemse como espaços em que se desenrolam complexos processos de semiose que vêm gerando, em diferentes níveis, tensões às práticas jornalísticas convencionais, o que acaba, potencialmente, produzindo zonas de fronteira nas quais linguagens interagem. É nesse cenário que se postula haver um momento de crise sistêmica pelo qual passa o jornalismo.

Como manifestação da crise, são trazidos à luz do debate acontecimentos suscitados pelo protesto " 25 S", promovido pelo movimento Indignados, na Espanha, em setembro de 2012, nos arredores do Congresso espanhol, e sua representação pelo jornal El País. Na ocasião, o garçom Alberto Casillas, de Madrid, roubou a cena ao enfrentar a ação truculenta da polícia, que tentava sufocar o protesto, produzindo intensa repercussão nas redes sociais e, consequentemente, chamando a atenção do jornalismo.

\section{A SEMIOSE NO CENTRO DO DIÁLOGO ENTRE PEIRCE E LOTMAN}

Pensar os processos de significação do mundo tendo a Semiótica da Cultura como uma das perspectivas é um gesto epistemológico que, ao mesmo tempo que supera a visada antropocêntrica na relação natureza, cultura e sociedade, reintroduz o sujeito humano conectado a outros níveis de complexidade (que é 
como se pensa a atuação do jornalista na condição de interpretante do signo)'. A cultura é, então, concebida em um jogo sistêmico através do qual, linguagens interagem e agem na construção social da realidade. A cultura, nessa perspectiva, é aquilo que organiza estruturalmente o mundo que cerca o ser humano e o torna capaz de ter consciência de si (LOTMAN, 2000).

Lotman e Uspenskii (1981), em trabalho conjunto, apontavam que somente a título de abstração científica a linguagem poderia ser delineada como um fenômeno em si mesmo. Mas, no seu funcionamento real, ela se encontra incorporada num sistema mais geral, o da cultura e, juntamente com este, constitui uma totalidade complexa. Os autores introduziam a perspectiva sistêmica no entendimento do processo na medida em que, para eles, o trabalho fundamental da cultura consiste em organizar estruturalmente o mundo que rodeia o homem. "A cultura é um gerador de estruturalidade: cria à volta do homem uma sociosfera que, da mesma maneira que a biosfera, torna possível a vida, não orgânica, é obvio, mas de relação" (LOTMAN; UNSPENSKII, 1981, p. 39).

Esse pensamento já contém o conceito de semiosfera que será definido mais tarde por Lotman (1996). Trata-se do espaço em que se processam e metabolizam-se toda e qualquer semiose: o espaço de constituição da própria cultura. Um espaço não homogêneo, mas provido de tensões, configurações e conflitos (HENN, 2011 a).

A semiose é, portanto, o elo entre a Semiótica da Cultura e a Teoria Geral dos Signos, de C.S. Peirce, sendo entendida como o processo de significação do mundo; de troca, de interação entre linguagens. É o processo que possibilita a organização do mundo pela linguagem. E é um conceito caro tanto para Lotman quanto para Peirce.

Peirce (2002) dedicou-se, acuradamente, a entender como se desenrolam os processos de produção de sentido sobre a realidade, inapreensível ao homem senão pela linguagem. E desse esforço faz-se a explicação triádica de que os fenômenos batem à consciência como qualidade (primeiridade), relação (secundidade) e representação (terceiridade). O signo, compreendido em sentido largo, é o mediador entre a realidade e o homem. Nesse sentido, há um objeto da realidade no qual age um interpretante de um signo que o representará e esse signo será objeto novamente, e assim sucessivamente, dando início a outras semioses.

A cultura, em Lotman (1999), é, ao mesmo tempo, fruto e 
semeadora da semiose. Fruto, quando se constitui pelos processos de semiose que produzem textos culturais e, assim, materialidades; semeadora, quando é base para que os processos de semiose estabeleçam-se, oferecendo mapas de significação a partir dos quais os fenômenos saem da primeridade, passam pela secundidade e chegam, nos signos já organizados em textos, à terceiridade.

Essa organização pode ser pensada em uma natureza sistêmica. Lotman e Uspenskii (1981) formulam uma ideia que tem implicada essa natureza, que pautaria a concepção de semiosfera: o crescimento da cultura, estruturada em mecanismos que oscilam entre a dinâmica e a estabilidade, posicionou a humanidade de forma vantajosa em relação as outras populações animais circunscritas a um volume estável de informação. Entretanto, há uma processualidade entrópica e dissipativa (no sentido de PRIGONINE, 1996)²: a cultura engole os recursos com a mesma avidez que o mecanismo produtivo e do mesmo modo destrói o ambiente que a envolve. Para eles, não são, a rigor, as exigências reais dos homens que ditam a velocidade desse comportamento, mas o que entra em jogo é a lógica interna da troca acelerada dos mecanismos internos operantes.

A estruturalidade da semiosfera tem um componente caótico dotado da mesma dinâmica dos chamados sistemas complexos. Para Lotman (1999), o mundo da semiose não está fatalmente fechado em si, mas forma uma estrutura complexa e heterogênea que continuamente joga com o espaço que Ihe é externo. E ao fazer isso, acentua a caoticidade do externo, dissipando sua organização. Essa relação do sistema com o mundo, que existe para além dele, será a relação do dinâmico com o estático, entre o homogêneo e o heterogêneo (HENN, 2010). A partir dessa perspectiva, o texto transforma-se em espaço semiótico no interior do qual as linguagens interagem, interferem-se e se auto-organizam hierarquicamente.

Trata-se de um espaço com alto teor de complexidade, que se articula em uma relação entre a estática e a dinâmica. Nessa perspectiva, há movimentos, próximos da estática, que são graduais, lentos, de mudanças quase imperceptíveis. Outros, porém, próximos da dinâmica, são imprevisíveis e de caráter explosivo. Todos os processos dinâmicos explosivos realizam-se em complexo diálogo com os mecanismos de estabilização, aspecto que evita a ideia de aniquilamento. Um dos fundamentos da semiosfera é, justamente, sua heterogeneidade. Para Lotman (1999, p. 159-160), 
Os sistemas semióticos dão prova, chocando-se na semiosfera, de tal capacidade de sobrevivência e transformação, e de transformarem-se em outros, como Proteo, permanecendo eles mesmos, que convém falar com muita prudência do desaparecimento total de qualquer coisa neste espaço.

O jornalismo, de grande protagonismo na produção semiosférica (e sujeito às oscilações previstas na dinâmica do sistema), é o que suscita o diálogo entre os dois autores neste trabalho. Primeiro, em Peirce (2002), o processo de produção da notícia, ou de narrativas jornalísticas, é entendido como uma semiose: a semiose da notícia (HENN, 1996; OLIVEIRA, 2012a). Assim, ao representar os acontecimentos na forma da notícia, o jornalista está numa constante produção de signos: o acontecimento é o objeto; por sua vez, o jornalista - não como sujeito, mas como mente afetada - atua na condição de interpretante; e a notícia representa o objeto enquanto signo. Daí é que se concebe o esquema lógico em que se tem, no seu interior: objeto/acontecimento - interpretante/ jornalista - signo/notícia. Esse esquema mobiliza um processo mais amplo que envolve o acontecimento (objeto), narrativa jornalística (construída na atividade interpretante do jornalismo) e sua repercussão/reverberação/agendamento (atividade interpretante em tensão como jornalismo).

Quanto a Lotman (1978), é evocado quando a compreensão sistêmica desses processos ganha evidência. O jornalismo como sistema de produção de sentido tem duas implicações sistêmicas fundantes: 1) a intervenção na construção social da realidade; 2) decorrente da primeira, a interação com outros sistemas de produção de sentido que permeiam a semiosfera. Desse modo, que semioses se estabelecem nos meandros dessas relações? Pistas para a resposta é o que a reflexão em curso pretende proporcionar.

\section{JORNALISMO COMO SISTEMA MODELIZANTE}

Toda a linguagem, do ponto de vista da Semiótica da Cultura, é um sistema modelizante. Isso quer dizer que, no seu funcionamento real, a linguagem encontra-se incorporada em sistema geral, compreendido como cultura em que a ação é essencialmente modelizante: a organização estrutural do mundo simbólico. Organização essa de caráter hipercomplexo e sujeita a 
vulnerabilidades diversas. As codificações instituídas pela linguagem jornalística, cujas lógicas encontram-se agora tensionadas na contemporaneidade, são expressões desse processo modelizante (HENN, $2011 \mathrm{~b}$; OLIVEIRA, 2012b).

A ideia de modelização tem ecos da cibernética, na medida em que é um modelo que sugere a abstração como ferramenta capaz de reproduzir objetos artificialmente: da observação, passando pela apreensão do seu funcionamento, ao controle. É aquilo que na cibernética se expressa no conceito de programa (MACHADO, 2003) e que Lotman e Unspenskii (1981) entendem como programa de comportamento que intervém na cultura como programa invertido: o programa olha para o futuro do ponto de vista de quem o elabora; a cultura olha para o passado do ponto de vista da realização do comportamento. Na linguagem, esse processo revela-se em semioses que se perpetuam e que produzem códigos culturais: "fontes de gestação da memória-hereditária, tal como entendeu Lotman, que se encarrega de formatar os sistemas semióticos da cultura" (MACHADO, 2003, p. 30).

Como sistema modelizante, os enquadramentos que o jornalismo aplica sobre os objetos da realidade tendem a se perpetuar, fenômeno que sugere a configuração de memórias coletivas como processos já previamente enquadrados na estruturação desses programas (HENN, 2008).

Uma ressalva importante: os sistemas modelizantes só podem ser compreendidos numa relação dialógica com um ou mais sistemas. É por isso que quando se reflete sobre o jornalismo é preciso pensar as suas relações com os demais sistemas que compõem a semiosfera. Dessa interação, saem os textos culturais sobre os quais o pesquisador pode dedicar atenção. Eles se configuram como a materialidade da pesquisa; demandam "mapas de significados", como propõem Stuart Hall et al (1993, p. 226): “Todos nós queremos manter basicamente a mesma perspectiva acerca dos acontecimentos. [...] o que nos une, como uma sociedade e cultura [...] ultrapassa [...] o que nos divide e distingue como grupos ou classes".

Como forma de consenso contemporâneo, toma-se o neoliberalismo como ideário dominante que organiza as relações sociais. O próprio Hall considera outros tipos de manifestações. Ao dizer, porém, que o "lado consensual se sobrepõe", legitima a interpretação de que há, na semiosfera, um sistema de significação com signos de caráter fortemente ideológico, com o 
qual o jornalismo interage, também como sistema.

Legi-signos, que é como Peirce (2002) designava os signos que, em relação a eles próprios, possuem a força de uma lei, podem ser pensados, na perspectiva aqui defendida, como categorias que orientam a produção de sentido sobre o mundo. Os acontecimentos jornalisticamente constituídos, mesmo estabelecidos em zonas de indeterminações icônicas e indiciais, estão fortemente amarrados a convenções históricas e culturalmente instituídas (HENN, 2010).

A produção da notícia é, portanto, uma semiose complexa, que sofre intervenções de várias ordens. Começa na pauta entregue ao repórter e passa por etapas consagradas: a redação do texto; o refinamento do editor; a eventual revisão do chefe de reportagem, do diretor de redação etc. Todos na direção da codificação à linguagem do veículo, conforme princípios de linha editorial ou manuais de redação. Portanto, as práticas jornalísticas podem ser entendidas também como legi-signos no sentido de que há toda uma codificação que se expressa em critérios de noticiabilidade, valores notícia, códigos de ética, culturas profissionais e outras normatizações que, em vários níveis, regulamentam esses processos.

Se na semiosfera predominam legi-signos que representam valores conservadores, mantenedores do consenso neoliberal, profissionais de redações seguem a regra. As práticas jornalísticas, conforme Manoff e Schudson (1986), acabam sendo orientadas pela aparência que a realidade assume nos processos de significação do mundo; e aí atuam as convenções, as rotinas, que moldam a percepção do jornalista e servem como repertório para a representação dos acontecimentos.

De um exercício etnográfico, realizado por Oliveira (2012c) durante pesquisa de mestrado em jornais gaúchos, resulta a elaboração de quatro categorias de legi-signos que incidem na semiose da notícia. A primeira categoria caracterizada foi a "Do neoliberalismo como ambiente semiótico", cuja ação diz respeito aos valores que mantêm o consenso neoliberal. $\mathrm{Na}$ segunda estão os legi-signos "Do jornalismo como sistema de produção de sentido", baseados nas convenções do campo. "Dos jornais como empresas de comunicação" são os legi-signos que dizem respeito à organização de cada periódico e, por fim, "Dos jornalistas como operadores sígnicos", aqueles que têm relação 
com a formação dos profissionais, seu common ground ${ }^{3}$ (PEIRCE, 2002).

As quatro categorias constituem-se como códigos culturais que determinam o funcionamento do jornalismo como sistema modelizante ${ }^{4}$. É com base nessa estrutura que os profissionais de redação significam o mundo, pelas semioses que os acontecimentos disparam. O resultado é a classificação do texto cultural produzido pelo jornalismo na função comunicativa definida por Lotman (1978), a que menos revela novos sentidos; é redundante em detrimento da função criadora e da função mnemônica.

\section{CRISE SISTÊMICA: TENSÕES ANTE A SEMIOSFERA CONTEMPORÂNEA}

Na semiosfera contemporânea da qual o jornalismo faz parte como sistema (HENN, 2002), novos agentes interagem, em uma trama que leva ao que está se chamando de crise sistêmica que as práticas jornalísticas atravessam. Sistêmica porque afetam parâmetros importantes, como autonomia e identidade, e podem redundar em transformações que, mesmo dominadas por forças centrípetas que agem na manutenção de determinados controles, alterariam fisionomias identitárias do jornalismo como campo profissional e acadêmico (HENN, $2011 \mathrm{~b}$ ).

Uma reflexão sob o prisma da contemporaneidade leva à conclusão de que, embora o protagonismo do jornalismo mantenha-se forte e a chancela dos formatos convencionais ainda concentre o estabelecimento das pautas públicas, outros sistemas começam a disputar com ele essa condição. As redes sociais, nesse contexto, são sistemas que têm, em níveis diferentes, mas constantemente, gerado tensões às práticas jornalísticas. Ao passo em que o jornalismo significa os acontecimentos numa semiose orientada pelos legi-signos que o compõem, nas redes sociais outras semioses desenrolam-se, configurando uma disputa de signos sobre a realidade. Na Figura 1, esboça-se uma tentativa de expressar essa elaboração. 
Figura 1 Esquema que representa o que se postula ser o circuito de significação dos acontecimentos em rede

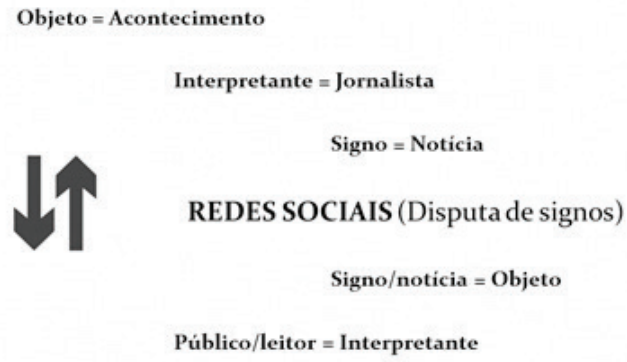

Fonte: desenvolvida pelos autores deste artigo.

Baseando-se nessa compreensão, os sentidos conferidos aos acontecimentos pelo jornalismo competem com aqueles que circulam nas redes sociais, a partir da intervenção de diferentes sujeitos, que operam diferentes semioses. É do que depreende-se que haja um movimento dialético de revisão das práticas, que pode impor aos profissionais de redação a tarefa de dar a ver mais dos acontecimentos. E nesse quadro é que surge o conceito de ciberacontecimento, que se refere à emergência de acontecimentos jornalísticos que já contenham, na sua constituição, a natureza das redes de compartilhamento da internet (HENN; HÖEHR, 2012).

O acontecimento, ao mesmo tempo que produz uma descontinuidade, afeta pessoas e sociedade em algum nível (QUERÉ, 2005). Sodré (2009) fala em “acontecimentalidade", que está vinculada a um complexo relacional entre materialidades, dimensão simbólica e afetividade de sujeitos que vivenciam de forma citadina o acontecimento. Boa parte dessa experiência do acontecimento é narrada inicialmente nas redes sociais, o que lhe confere um grau de pertinência importante. Também as mídias locativas permitem uma aproximação mais orgânica com os acontecimentos que podem ser desvendados em tons diferenciados, com outras possibilidades de fontes.

Esse conjunto de conexões forma hoje um ambiente semiosférico constitutivo dessa nova modalidade de acontecimento (e que não é homogênea, já que pode revelar situações sociais de grande densidade assim como processos absolutamente supérfluos) e tendem a problematizar os fluxos tradicionais da produção das narrativas jornalísticas. Desse modo, a existência pública do acontecimento tem no jornalismo seu locus preferencial de 
legitimidade e foco potencial de sua afetação e reverberação. Tratase de uma semiose, cujo fluxo pautava-se, até então, por certa linearidade na transformação do objeto semiótico (acontecimento) em signo (narrativa jornalística), com produção de interpretantes (repercussão, afetação, agendamento). Essa lógica vem sendo reiteradamente abalada pelos processos de comunicação on-line e ganha texturas instigantes com a consolidação das redes sociais na internet (HENN, 201 1b; HENN; HÖEHR, 2012).

No caso que se passa a descrever agora, há diversas manifestações desse movimento. Em 25 de setembro de 2012, milhares de pessoas vão às ruas de Madrid, na Espanha, durante o "25S”, protesto organizado pelo Indignados, um dos grupos que aderem aos movimentos de ocupação global em todo o mundo, defendendo demandas das minorias, melhor distribuição de renda e modelos alternativos de organização social, especialmente na Europa e nos Estados Unidos 5 , cuja principal bandeira é a democracia real - ou direta. Dessa vez, a pauta inclui a reivindicação de uma nova assembleia constituinte; uma praça em frente ao Congresso espanhol é ocupada.

Eis o acontecimento: manifestação do Indignados que mobiliza a sociedade por uma nova constituinte, na expectativa de superar o que os manifestantes entendem ser a defasagem da atual constituição do país, um dos motivos para a desigualdade social e a falta de políticas públicas que atendam aos mais necessitados.

Figura 2 Capa da seção criada para a cobertura do "25S" na página eletrônica do El País

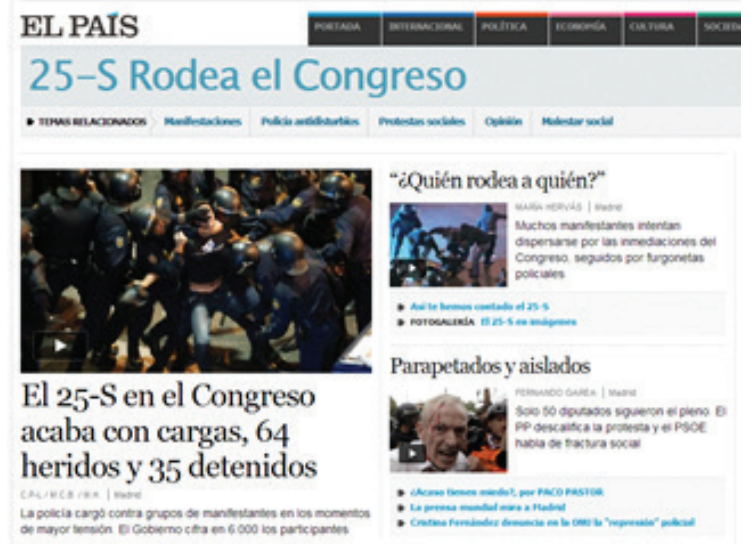

Fonte: disponível em http://politica.elpais.com/tag/manifestacion_25_ septiembre_2012/a/. Acesso em: 04 jan. 2013. 
$\mathrm{Na}$ ocasião, índices de notabilidade que definem o que seja o estatuto do acontecimento jornalisticamente constituído (BENETTI, 2010), com os legi-signos que o determinam, são contemplados. Prova é que o principal jornal espanhol, o El País, publica em sua página eletrônica uma seção especial para as manifestações; para a sua representação como objeto de signos/notícia (Figura 2). E um dos signos/notícia publicados no dia 25 de setembro tem como título "Quem rodeia quem"6, em alusão ao Congresso cercado pelos manifestantes; uma tentativa de explicar o que é o movimento, sua origem, e quem o compõe. Embora o texto aborde o clima de apreensão causado por protestos mais radicais, omite atos de violência da polícia.

Nas primeiras horas do dia seguinte, entre as notícias que o periódico publica está a de título "Protesto do 25S termina com carga, 64 feridos e 35 presos"7; o texto trata da ação policial, que visava evitar que os manifestantes invadissem o Congresso e, como o próprio título sugere, faz um balanço das consequências. Até aí, contudo, a significação do acontecimento não dá espaço para denúncias de violência. Ao contrário: o procedimento policial é legitimado pelo discurso que se produz.

Figura 3 Memes que circularam na rede, em alusão à atuação de Alberto Casillas

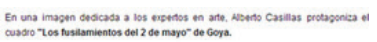

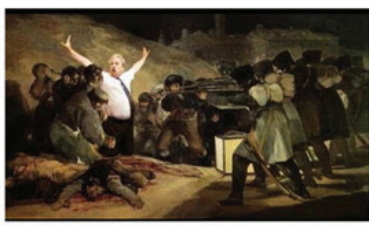

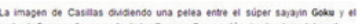

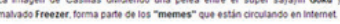

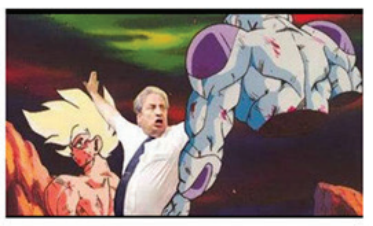

Tamsitn es posiele ver a casilus separanso is peles ocumba ente Zinesine

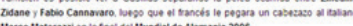

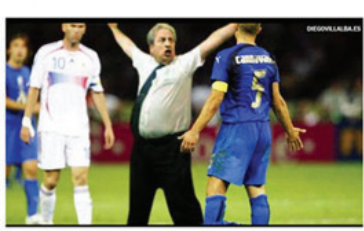

Fonte: disponível em http://www.24horas.cl/internacional/heroe-del-25-sse-convierte-en-la-sensacion-de-la-web-324665. Acesso em: 04 jan 2013. 
Paralelamente à cobertura conferida pelo El País, começa a circular nas redes sociais, sobretudo no Facebook e no Twitter, denúncias publicadas pelos próprios manifestantes ou por cidadãos que não participavam do movimento, mas presenciavam o acontecimento.

O auge é a publicação, no YouTube, de um vídeo em que o garçom Alberto Casillas - sua identificação só seria possível mais tarde, depois que o fenômeno chamou a atenção do jornalismo - aparece defendendo os manifestantes que se refugiam no estabelecimento em que ele trabalha e impedindo a entrada dos policiais ${ }^{8}$. Isso já no dia seguinte ao início das manifestações, em 26 de setembro.

O vídeo, como signo que representa a ação do garçom como objeto, dispara uma semiose que leva à produção de diversos memes replicados nas redes sociais (Figura 3). O perfil no Twitter, que identifica Casillas como usuário (twitter.com/ PorterodelPrado), passa a contar rapidamente com um número significativo de seguidores. E basta uma busca ligeira no Facebook para se encontrar páginas criadas em sua homenagem ${ }^{9}$.

No final do dia 26 de setembro, o El País publica entrevista concedida pelo garçom sob o título "Eu sou do PP, mas a polícia foi excessiva"10. Alberto Casillas admite ser filiado e eleitor do Partido Popular (PP), de orientação conservadora e que está no governo espanhol, o que não o impede de ser crítico à ação violenta da polícia, razão pela qual decidiu intervir em defesa dos manifestantes. É a primeira vez que a violência policial é significada como parte do acontecimento "25S".

$\mathrm{Na}$ interação entre sistemas, o jornalismo é afetado pelas redes sociais, no que se aponta uma das zonas de fronteira que se estabelecem na semiosfera contemporânea. E é exatamente nas fronteiras do sistema, espaços de permeabilidades e traduções, que Lotman (1999) percebia a possibilidade de crises, algumas de caráter explosivo e desencadeadoras de mudanças significativas no caráter produtivo e semiótico do ambiente.

É desse contato entre os sistemas que emergem novos sentidos para o acontecimento "25S", para além daqueles dados pelos textos inicialmente produzidos pelo jornalismo, que exercem a função comunicativa. O texto que sai dessa interação, à sua parte, carrega, potencialmente, a função geradora de que fala Lotman (1978). E a interação entre dois textos distintos, o do jornalismo e o das redes sociais, só é possível pela ação, também, 
da função mnemônica, que os põem em diálogo ao conservar os códigos de linguagem, mas significando os acontecimentos adiante. A memória é pensada não apenas como a que se volta para o passado e, sim, para o futuro, proporcionando novos arranjos na combinação dos códigos.

\title{
4 PERSPECTIVAS PARA O ESTUDO DO JORNALISMO
}

A truculência com que os protestos foram repreendidos em detrimento do grande acontecimento (a tentativa de ocupação do Congresso) foi cinicamente percebida como ordinária, comum, nas palavras de Benetti (2010); não ascendeu à condição de acontecimento jornalístico. Isso em razão dos legi-signos que orientam a produção de sentido no jornalismo, que preservam a ordem acima das demais implicações do protesto promovido pelo Indignados.

Os primeiros signos/notícias que representam o "25S" como objeto dão a ver, no máximo, da quantidade de feridos em decorrência da ação policial. Só depois de um movimento de significação em massa nas redes sociais, denunciando os abusos, com Casillas como personagem, os excessos passam a ser significados como objeto de novos signos/notícia, no que parece ser expressão da disputa de signos.

Para Gumersindo Lafuente, diretor do jornal espanhol El País:

\begin{abstract}
A internet colocou o jornalismo e os jornalistas em um novo lugar, mais exposto, mais complicado e mais comprometido. Esse lugar está cheio de oportunidades, mas também tem novas obrigações. Passamos do oligopólio à desintermidiação quase total, e hoje somos imprescindíveis nas relações entre os poderes e temos aí os cidadãos reivindicando nosso papel minuto a minuto (LAFUENTE, 2011$)^{11}$.
\end{abstract}

A opinião do jornalista constitui-se em indício da forma como os profissionais de redação estão percebendo a incidência das redes no seu fazer. Corrobora, assim, com a proposição de que há uma crise sistêmica, gerada pelas redes, que tensiona as práticas jornalísticas convencionais e impõem ao jornalismo um movimento de reflexão.

Com a pretensão de estimular essa reflexão, propõe-se a semiótica como um dos lugares a partir dos quais ela pode ir adiante. E, em especial, quando se tem a Semiótica da Cultura como perspectiva, destaca-se uma visão sistêmica, de modo a dar 
conta de avaliar as interações que se desencadeiam na semiosfera a partir da significação dos acontecimentos. Como advoga Machado (2003, p. 27): “A ideia de que a cultura é a combinatória de sistemas de signos, cada um com codificação própria, é a máxima da abordagem semiótica da cultura que se definiu, assim, como uma semiótica sistema"12.

É diante desses parâmetros que o trabalho do pesquisador, disposto a debruçar-se sobre os acontecimentos para uma análise semiótica, deve estar atento às lógicas que incidem nas semioses que os sistemas de produção de sentido disparam. Como ensina Peirce (1974, p. 23):

Fique entendido, então, que o que temos a fazer, como estudantes de fenomenologia, é simplesmente abrir nossos olhos mentais, olhar bem para o fenômeno e dizer quais são as características que nele nunca estão ausentes, seja este fenômeno algo que a experiência externa força sobre nossa atenção, ou seja, o mais selvagem dos sonhos ou a mais abstrata e geral das conclusões da ciência.

Convém ressalvar que tensões ao jornalismo como sistema não são fenômenos novos. Desde os estudos culturais, quando a recepção deixa de ocupar papel de coadjuvante nos processos de significação do mundo, problemas dessa ordem têm sido considerados. Com a emergência das redes sociais, no entanto, sempre entendidas como sistemas, essas tensões intensificam-se. Mais do que isso: é possível, pela materialidade dos textos que se produzem nas fronteiras da semiosfera contemporânea, que as consequências sejam analisadas (SALLES, 2011; HENN, 2011 b). Foi o esforço demandado por este artigo. Como reivindica Christa Berger (2010, p. 24-25), é preciso aprofundar o diálogo entre a prática e o conhecimento sobre o jornalismo, proporcionando diálogos menos dissonantes entre saber e fazer "na esperança de que o jornalismo possa, ao informar sobre a realidade, contribuir para o esclarecimento do mundo".

Ao encontro de Christa Berger, a avaliação que fica é a de que o momento de crise é fértil para um debate sobre a contribuição que o jornalismo pode dar a um projeto emancipatório de sociedade. Ao produzir conhecimento, dotando os indivíduos de um saber de si-em um tímido flerte com a hermenêutica do sujeito, de Foucault (2006) -, de racionalidade comunicacional, o jornalismo os tornaria capazes de exercer a ação comunicativa com vistas ao bem comum de que fala Habermas (2003). E é preciso fazê-lo tendo como ideal 
o talento poliédrico, em Lotman (1999), referido por Machado (2003, p. 23) como: "[...] inteligências cuja capacidade criadora não enxerga limites, podendo estabelecer conexões onde muitos só veem compartilhamentos e ver problemas onde o senso comum já fixou verdades".

Por fim, não é demasia chamar a atenção para o caráter aberto de uma proposta sistêmica para o estudo do jornalismo ou de qualquer fenômeno no âmbito das ciências humanas, uma vez que a semiose dos objetos não para nas conclusões a que se chega com o término de uma análise. Para Regiane Nakagawa (2012, informação verbal) ${ }^{13}$, o pesquisador vai, na fronteira que se estabelece no contato com o objeto, até o que é possível apreender em determinado momento e tendo em vista um contexto específico. O desafio é produzir inferências que efetivamente contribuam à sua compreensão.

\section{NOTAS}

1 "Se linguagem ocorre em escalas que estão além do processo de interação social, isto é, que abarcam o bio, o cosmos, o semion, não há como fechar a cultura no socius. Entender a interação entre natureza e cultura é, de fato, o grande problema para a abordagem semiótica da cultura de extração russa" (MACHADO, 2003, p. 25).

2 São processos auto-organizacionais ou autorregeneradores disparados por um tempo irreversível, como postula Prigonini (apud HENN, $2011 \mathrm{a}$ ).

3 Em livre tradução: fundamento comum.

4 Para saber mais sobre as quatro categorias de legi-signos ver: Oliveira (2012c).

5 Nos Estados Unidos, o exemplo de mais repercussão entre os movimentos de ocupação global: Occupy Wall Street.

6 Livre tradução do autor da Língua Espanhola para a Língua Portuguesa. Original disponível em: http://politica.elpais.com/ politica/2012/09/25/actualidad/1348599210_154793.html. Acesso em 04 jan 2013.

7 Livre tradução do autor da Língua Espanhola para a Língua Portuguesa. Original disponível em: http://politica.elpais.com/ 
politica/2012/09/25/actualidad/1348574519_035448.html. Acesso em 04 jan 2013.

8 Vídeo Disponível em: http://www.youtube.com/watch?feature =player_embedded\&v=pZkmSREGETs\#. Acesso em: 04 jan 2013.

9 Como exemplos, ver: http://www.facebook.com/ AnimaAAlbertoCasillasAQuemarSuCarnetDelPp e http://www. facebook.com/pages/Hommage-\%C $3 \%$ A 0-Alberto-Casillas /154936717983883. Acesso em: 04 jan 2013.

10 Livre tradução do autor da Língua Espanhola para a Língua Portuguesa. Original disponível em: http://ccaa.elpais.com/ccaa/2012/09/26/ madrid/1348680731_595925.html. Acesso em 04 jan 2013.

11 Entrevista concedida ao repórter Lucas Hackradt, da revista Época, publicada na versão on-line em 08 de setembro de 2011 . Disponível em: http://revistaepoca.globo.com/Sociedade/A-decada-da-In ternet/noticia/2011/09/gumersindo-lafuente-internet-colocou-ojornalismo-e-os-jornalistas-em-um-novo-lugar.html. Acesso em: 09 dez 2012.

12 Grifos conforme o original.

13 Apontamento de aula ministrada pela professora Dra. Regiane Miranda de Oliveira Nakagawa, no dia 27 de novembro de 2012, durante o seminário Semiótica da Cultura, promovido pelo PPCCOM da UFRCS.

\section{REFERÊNCIAS}

BENETTI, Marcia. O jornalismo como gênero discursivo. Galáxia, São Paulo, n. 15, 2008.

BENETTI, Marcia. O jornalismo como acontecimento. In: BENETTI, Marcia; FONSECA, Virginia. Jornalismo e Acontecimento. Mapeamentos críticos. Florianópolis: Insular, 2010. p. 143-164.

BERGER, Christa. O conhecimento do jornalismo no círculo hermenêutico. Brazilian Journalism Research, v. 6, n 2, p. 17-25, 2010.

BERGER, Peter; LUCKMANN, Thomas. A construção social da realidade. Tratado de Sociologia do Conhecimento. Petrópolis: Vozes, 1983. 
FOUCAULT, Michel. A hermenêutica do sujeito. 2. ed. São Paulo: Martins Fortes, 2006.

HABERMAS, Jürgen. Mudança estrutural da esfera pública: investigações quanto a uma categoria da sociedade burguesa. 2. ed. Rio de Janeiro: Tempo Brasileiro, 2003.

HALL, Stuart et. al. A produção social das notícias: o mugging nos media. In: TRAQUINA, Nelson (Org.). Jornalismo: questões, teorias e estórias. Lisboa: Vega, 1993. p. 224-247.

HENN, Ronaldo. Pauta e Notícia: Uma abordagem semiótica. Canoas: Ulbra, 1996.

Os fluxos da notícia. São Leopoldo: Unisinos, 2002.

Jornalismo como semiótica da realidade social. Compós, 2008. Disponível em: <http://www.compos.org.br/data/biblioteca_375. pdf>. Acesso: 25 jun. 2012.

O acontecimento em sua dimensão semiótica. In: BENETTI, Marcia; FONSECA, Virginia (Orgs). Jornalismo e Acontecimento. Mapeamentos críticos. Florianópolis: Insular, 2010 . p. 77-92.

Memória e arte na semiosfera midiatizada. In: Conexão, comunicação e cultura, v. 10, n. 18. Caxias do Sul: UCS, 2011 a. p. 103-115.

Acontecimento em rede: crises e processos. In: LEAL, B., ANTUNES, E.; E VAZ, P. (org), Jornalismo e Acontecimento. Percursos Metodológicos. Florianópolis: Insular, 2011 b. p. 79-96.

HENN, Ronaldo; HÖEHR, Kellen. Transformations of the journalistic event in social networks: the mobilizations against homophobia to the crisis of country music duo. Brazilian Journalism Research, $n$. 8 v. $1,2012$.

LOTMAN, Yuri. A Estrutura do Texto Artístico. Tradução de Maria do Carmo Vieira Raposo e Alberto Raposo. Lisboa: Estampa, 1978.

La semiosfera I. Tradução e seleção de Desiderio Navarro. Madrid: Edicones Frónesis Cátedra Universitat de València, 1996.

La semiosfera III. Semiótica de la Cultura e del Texto. Tradução e seleção de Desiderio Navarro. Madrid: Edicones Frónesis Cátedra Universitat de València, 2000.

Cultura y explosión, Lo previsible en los processos de cambio social. Barcelona: Gedisa Editorial, 1999.

LOTMAN, Yuri; USPENSKII, Boris et al. Ensaios de Semiótica Soviética. Lisboa: Horizonte Universitário, 1981. 
MACHADO, Irene. Escola de Semiótica. A experiência de TártuMoscou para o Estudo da Cultura. São Paulo: Ateliê Editorial, 2003.

MANOFF, Robert Karl; SCHUDSON, Michael. Reading the news. New York: Pantheon Books, 1986.

MEDITSCH, Eduardo. O Jornalismo é uma forma de conhecimento? 1997. Disponível em: <http://www.bocc.ubi.pt/pag/meditscheduardo-jornalismo-conhecimento.pdf>. Acesso: 18 jul 2012.

OLIVEIRA, Felipe de. A semiose da notícia: por um lugar epistêmico para o estudo do Jornalismo. Congresso da Intercom, Fortaleza (CE): Unifor, 2012a. Disponível em: http://www.intercom.org.br/papers/ nacionais/2012/resumos/R7-1810-1.pdf. Acesso em: 21 jan. 2013.

O Dia do Trabalhador do Jornal Nacional: Reflexões sobre jornalismo e construção social da realidade. Congresso da SBPJor, Curitiba (PR): PUCPR, 2012b. Disponível em: http://soac.bce.unb.br/ index.php/ENPJor/XENPJOR/paper/viewFile/1785/120. Acesso: 21 jan. 2013.

Produção da notícia e movimentos sociais: processos de produção no Jornalismo. 2012. 286f. Dissertação (Mestrado em Ciências da Comunicação) - Programa de Pós-Graduação em Ciências da Comunicação. São Leopoldo, RS: Universidade do Vale do Rio dos Sinos, 2012c.

PEIRCE, Charles S. Escritos coligidos. Seleção de Armando Mora D’Oliveira. 3. ed. São Paulo: Abril Cultural, 1974.

The Collected Papers of Charles Sanders Peirce. Past Masters, CD-ROM. EUA: InteLex Corporation, 2002.

QUÉRÉ, Louis. Entre facto e sentido: a dualidade do acontecimento. Trajectos - Revista de Comunicação, Cultura e Educação. Lisboa, n. 6, 2005, p. 59-76.

SALLES, Cecília. Jornalismo em processo. Grupo de Trabalho Estudos de Jornalismo do XX Encontro da Compós. Porto Alegre (RS): UFRCS, 2011 . Disponível em http://www.compos.org.br/. Acesso: 14 mar. 2013.

SANTAELLA, Lúcia. Produção de linguagem e ideologia. São Paulo: Cortez, 1996.

SODRÉ, Muniz. A narração do fato: notas sobre uma teoria do acontecimento. Petrópolis: Vozes, 2009. 
SROUR, R. H. Modos de produção: elementos da problemática. Rio de Janeiro: Graal, 1978.

Felipe Moura de Oliveira é jornalista, mestre e doutorando em Ciências da Comunicação (Unisinos), linha de pesquisa Linguagem e Práticas Jornalísticas (LP2). Bolsista de doutorado do CNPq. Cursa também graduação em Ciências Sociais na UFRGS. E-mail: felipecomunica@gmail. com.

Ronaldo Henn é jornalista, mestre e doutor em Comunicação e Semiótica pela PUCSP. Atua como professor pesquisador no PPG em Ciências da Comunicação da Unisinos. E-mail: henn.ronaldo@ gmail.com. 